\title{
Mechanical and Energy Absorption Properties of Foamed Concrete under One-dimension Strain Compression
}

\author{
Tian Xinbang ${ }^{1,2}$, Zhang Daiyu ${ }^{3} \&$ Niu Yunhui ${ }^{4}$ \\ ${ }^{1}$ State Key Laboratory of Explosion Science and Technology, Beijing Institute of Technology, Beijing, China \\ ${ }^{2}$ Key Laboratory of Solid Waste Treatment and Resource Recycle, Ministry of Education, Southwest University \\ of Science and Technology, Sichuan, China \\ ${ }^{3}$ Department of Mining Engineering, School of Environment and Resource, Southwest University of Science \\ and Technology, Sichuan, China \\ ${ }^{4}$ Sichuan Province Key Laboratory for Nonmetal Composites and Functional Materials, Southwest University of \\ Science and Technology, Sichuan, China \\ Correspondence: Tian Xinbang, Key Laboratory of Solid Waste Treatment and Resource Recycle, Ministry of \\ Education, Southwest University of Science and Technology, Sichuan, China. Tel: 86138-8117-9432. E-mail: \\ 843302303@qq.com
}

Received: December 18, 2015

Accepted: March 15, 2016

Online Published: May 24, 2016

doi:10.5539/mas.v10n7p195

URL: http://dx.doi.org/10.5539/mas.v10n7p195

\begin{abstract}
Foamed concrete is a type of cellular concrete with excellent properties of impact attenuation and energy absorption. This study investigates the mechanical and energy absorption properties of foamed concrete. The relationship between elastic modulus and relative density of foamed concrete was exploited at one-dimension strain compressive loading condition, and a shape function was applied to describe the constitutive equation of the foamed concrete. In this study one-dimension strain compressive testing method was employed. Based on stress strain curve and constitutive equation, yield stress, plateau stress, densification strain and energy absorption efficiency of foamed concrete were obtained, and the energy absorption property was also analyzed. This study can support the applications of foamed concrete in structural protection.
\end{abstract}

Keyword: foamed concrete, mechanical properties, densification strain, energy absorption

\section{Introduction}

Foamed concrete is a type of cellular materials with lower strength(Weigler \& Karl, 1980; Jones \& Mccarthy, 2005), acoustic insulation, freeze-thaw resistance(Tikalsky, Pospisil \& Macdonald, 2004)and high-impact resistance(Zollo \& Hays, 1998). The basic constituents of foamed concrete are fine sand, cement, water and uniformly distributed cells in the form of small bubbles(Weigler \& Karl, 1980; Hoff, 1972). Foamed concrete can be designed to have any density in range of $170-1600 \mathrm{~kg} / \mathrm{m}^{3}$, and now it is widely used as structure materials in civil engineering field. Sometimes they are also applied in defense engineering as core materials of protective structure against impact or blast loads. In the protective engineering, foamed concrete is usually used in sandwiched structure, and it currently has become more and more attention especially in aircraft arresting system and military protection engineering.

The mechanical properties of foamed concrete under conventional concrete uniaxial compression was studied by several researchers (Zollo \& Hays, 1998; Shang, Li, Chen \& Xiao, 2012; Zhou, Lu, Jiao \& Li, 2010; Xiong \& Yao, 2010; Li, Guo, Zhao \& Shi, 2012). In their study a phenomenological constitutive equation of foamed concrete was developed, however that equation only can describe the deformation before the densification of foamed concrete, and the density of foamed concrete they studied had a density ranging from 180 to $370 \mathrm{~kg} / \mathrm{m}^{3}$. The behaviour of foamed concrete under confined compression was studied by other researchers(Zollo \& Hays, 1998), and the stress-strain curves up to the fracture points of foamed concrete were addressed. Fig1 shows two stress-strain curve resulted from confined condition(Mohd, Mujahid, Zaidi \& Ismail, 2010) and unconfined condition(Xiong, 2008). 


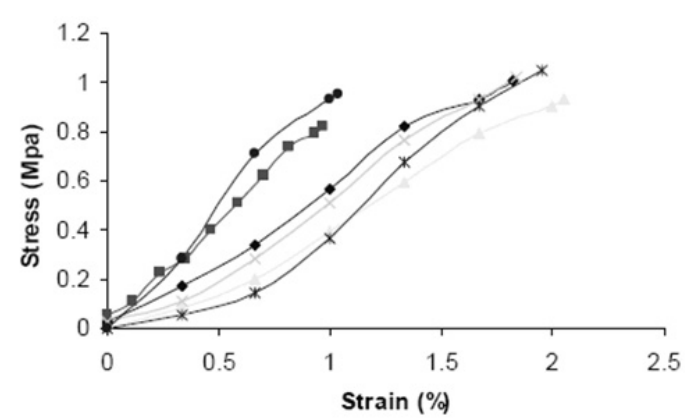

(a)

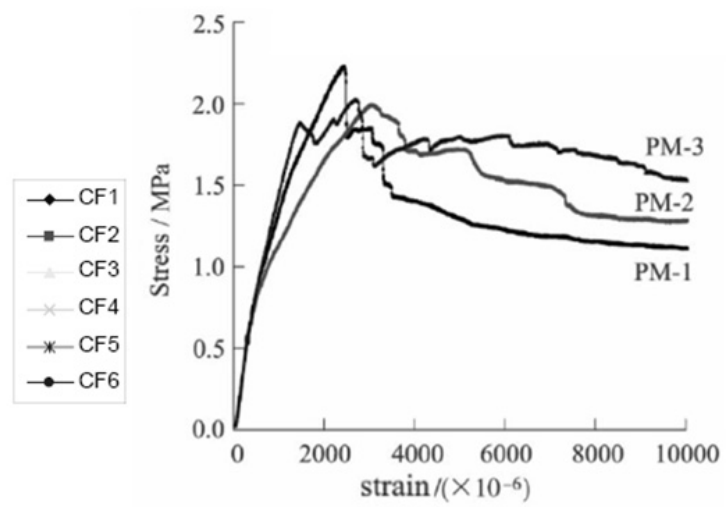

(b)

Figure 1. Two tested stress-strain curve of foamed concrete (a) confined compression(Mohd, Mujahid, Zaidi \& Ismail, 2010); (b) unconfined condition (Xiong, 2008)

Based on morphology and meso-mechanical analysis, as a type of cellular materials, the behaviour of foamed concrete should be similar to that of cellular material under compression(Abdul, 2008; Zaudi, Rahman \& Zaidi, 2008). The typical stress-strain curve of cellular material under compressive loading condition can be divided into three regimes, namely elastic regime, plateau regime and densification regime, as illustrated in Fig 2 (Mohd, Mujahid, Zaidi \& Ismail, 2010).

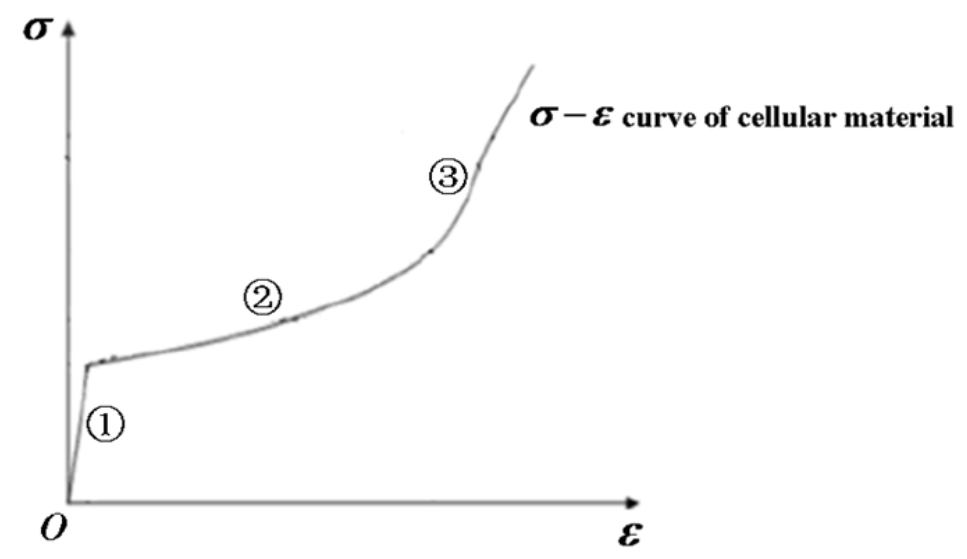

Figure 1. Typical three-regime stress-strain curve of cellular material, (1)elastic regime, (2)plateau regime and (3)densification regime(Mohd, Mujahid, Zaidi \& Ismail, 2010)

However proved by further experiment, conventional compressive testing method for concrete test can not be adequate for mechanical behaviour investigation of foamed concrete, because the three-regime stress-strain curve cannot be acquired by this method for dissimilar deforming mechanism of foamed concrete to universal concrete. Therefore, in order to fully understand the mechanical behaviour of foamed concrete, an unusual experimental system is employed to perform the compression test of foamed concrete, and the system is called one-dimension strain loading method.

For foamed concrete used in defense engineering will be always lied in uniaxual strain state in the loading direction, while in other two direction in firmly constrained states, the uniaxial compression behavior will make foamed concrete experience a large plastic deformation until full densification. Identification of the mechanical and energy absorption properties of foamed concrete is a critical step toward understanding of the foamed concrete's mechanical properties under the impact or explosion loading.

In this work, we systematically investigated the mechanical properties and energy absorption of foamed concrete under one-dimension strain loading condition. A modified confined uniaxial compression testing method was 
employed, which was once utilized by seldom other researchers (Zollo \& Hays, 1998; Xiong, 2008; Luo, 2011; Liu, Zhao, Wang \& Ren, 2007).

\section{Experiment and Material}

\subsection{Theory of One-Dimension Strain Loading Test}

One-dimension strain loading test is totally different from conventional concrete compressive test. Transversely passive constraint, made by steel, is applied during loading axially on specimen in our work. This experimental apparatus is an effective method for studying mechanical behaviour of brittle foam materials and can be attributed to the plane axial symmetry problem with equilibrium equation.

In the presence of axial symmetry condition $\sigma_{\theta}=\sigma_{\theta}(r), \sigma_{r}=\sigma_{r}(r), \sigma_{z}=$ const. , the deformation compatibility equations in polar coordinate can be written by

$$
\begin{gathered}
\frac{\mathrm{d} \sigma_{r}}{\mathrm{~d} r}+\frac{\sigma_{r}-\sigma_{\theta}}{r}=0 \\
\frac{\mathrm{d}^{2}}{\mathrm{~d} r^{2}}\left(\sigma_{r}+\sigma_{\theta}\right)+\frac{1}{r} \frac{\mathrm{d}}{\mathrm{d} r}\left(\sigma_{r}+\sigma_{\theta}\right)=0
\end{gathered}
$$

Substitutes formula (1) into (2), we can obtain

$$
\frac{\mathrm{d}^{3} \sigma_{r}}{\mathrm{~d} r^{3}}+\frac{3}{r} \frac{\mathrm{d}^{2} \sigma_{r}}{\mathrm{~d} r^{2}}+\frac{1}{r^{2}} \frac{\mathrm{d} \sigma_{r}}{\mathrm{~d} r}=0
$$

The general solution of (1), (2)and (3) is

$$
\begin{gathered}
\sigma_{r}=-\frac{A}{2} r^{-2}+B \ln r+C \\
\sigma_{\theta}=\frac{A}{2} r^{-2}+B \ln r+C+B
\end{gathered}
$$

where $A, B$ and $C$ are constants and can be determined by boundary condition between specimen and lateral constraint and external free boundary of the constrain. For current experiment, $\sigma_{r}$ remains independent of the polar radius $r$ so that $A=B=0$, then we have

$$
\varepsilon_{r}=\varepsilon_{\theta}=\frac{1-v_{1}}{E_{1}} C-\frac{v_{1}}{E_{1}} \sigma_{z}
$$

this equation expresses the plane hydrostatic pressured state. Suppose $\boldsymbol{u}_{r}$ is radial displacement then $\varepsilon_{r}=\frac{\mathrm{d} u_{r}}{\mathrm{~d} r}$, the corresponding boundary condition can be written as $\left.\sigma_{r}\right|_{r=a+t}=0,\left.u_{r}\right|_{r=a^{+}}=\left.u_{r}\right|_{r=a^{-}}$, $\left.\sigma_{r}\right|_{r=a^{+}}=\left.\sigma_{r}\right|_{r=a^{-}}$, here $t$ indicates the thickness of rigid constrain wall. Considering one dimension stress state, the boundary condition is $\left.\sigma_{r}\right|_{r=a}=0$, then radial strain solution without lateral constrain would be

$$
\varepsilon_{r 1 \mathrm{D} \text { stress }}=\varepsilon_{\theta 1 \mathrm{D} \text { stress }}=-\frac{v_{1}}{E_{1}} \sigma_{z}
$$

For cellular material including foamed concrete, Poison's ratio would be approximately set to zero. So $\boldsymbol{\varepsilon}_{r 1 \mathrm{D} \text { stress }}=\boldsymbol{\varepsilon}_{\boldsymbol{\theta} 1 \mathrm{D} \text { stress }}=0$ under rigid confined test condition, which exactly corresponds to one-dimension quasi-static strain state and makes the basis of this research work. The internal radius of steel sleeve used here is identical with the outer radius of specimen and the thickness of the steel sleeve wall is $t=5 \mathrm{~mm}$, shown in Fig3.

Liu F et al analyzed the effect of steel sleeve on radial strain of soft and porous materials under one-dimension 
strain compression(Liu, Zhao, Wang \& Ren, 2007). Their study showed that when brittle foam materials subjected to compression, the lateral deformation of specimen could be neglected, because the modulus of steel sleeve applied as lateral constraint was far greater than that of foamed concrete and the Poisson's ratio of foamed concrete equaled approximately to zero. In addition, there were no heat generation and scuff marks on internal surface of steel sleeve during experiment, which also proved that neglecting lateral deformation of specimen was reasonable. Therefore for foamed concrete, Poison's ratio could be suggested to be zero, and then we got $\boldsymbol{\varepsilon}_{r 1 \mathrm{D} \text { stress }}=\boldsymbol{\varepsilon}_{\boldsymbol{\theta} 1 \mathrm{D} \text { stress }}=0$, which makes the basis of this work.

The thickness of the steel sleeve wall is $t=5 \mathrm{~mm}$, which is illustrated in Fig3. In order to further eliminate the effects of steel sleeve on experimental results, lubricant was daubed within the internal wall of steel sleeve.

\subsection{Specimen Preparation}

The tested foamed concrete is a closed cell brittle foam, and made of a combination of fine sand, cement, water and cellular cell. Foamed concrete specimen are designed to meet Chinese standard GB T208. The basic components of foamed concrete is shown in Table1. Two types of foamed concrete, namely $400 \mathrm{~kg} / \mathrm{m}^{3}$ and $800 \mathrm{~kg} / \mathrm{m}^{3}$ in density, are tested in our study.

Table 1. Basic components of foamed concrete

\begin{tabular}{cccc}
\hline \multicolumn{2}{c}{ matrix $/ \%$} & \multicolumn{2}{c}{ foaming agent } \\
\hline 42.5R cement & fly ash & nominal density $/ \mathrm{kg} / \mathrm{m}^{3}$ & water-agent ratio \\
\hline 80 & 20 & 400 & 0.3 \\
80 & 20 & 800 & 0.3 \\
\hline
\end{tabular}

Porosity is commonly used to describe the quantity of cellular cells contained in foam materials(Zhao, Luo \& Wang, 2012), which is defined by

$$
\phi=1-\frac{\rho^{*}}{\rho_{s}}
$$

where $\rho^{*}$ is the apparent density of foamed concrete and $\rho_{s}$, the density of matrix consisting of foamed concrete. The porosity of the tested sample is $67.3 \%$ and $83.2 \%$, and the designed compressive strengths are $1 \mathrm{MPa}$ and $5 \mathrm{MPa}$ for density of $800 \mathrm{~kg} / \mathrm{m}^{3}$ and $400 \mathrm{~kg} / \mathrm{m}^{3}$ of foamed concrete, respectively.

The foamed concrete specimens consist of solid cell walls and a great mount of entrained air bubbles with cell size of $1-3 \mathrm{~mm}$. So the foamed concrete specimen with dimension of $50 \mathrm{~mm}$ in diameter and $100 \mathrm{~mm}$ in height should comprise of sufficient cellular cells and could be regard as homogeneous material. Fig2 shows the photograph of the specimens and its SEM image.
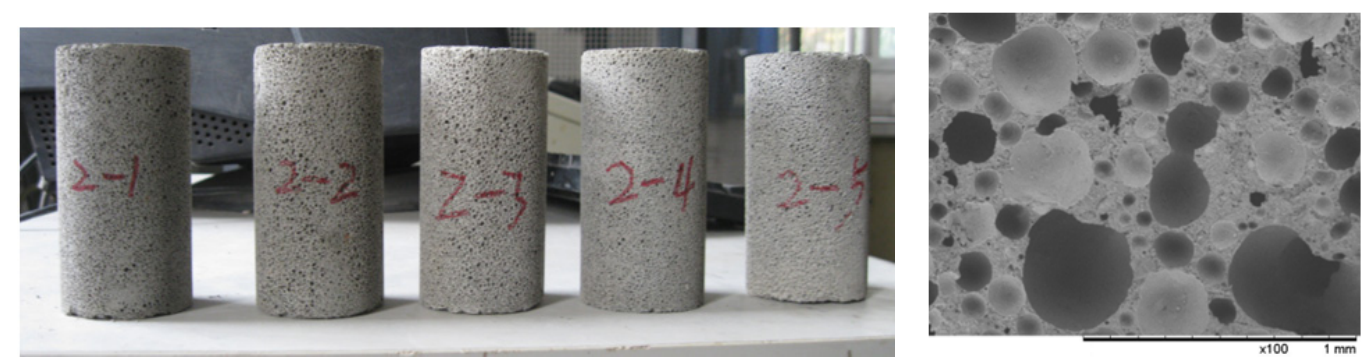

Figure 2. Foamed concrete specimens and its SEM image

\subsection{Test Setup}

Considering the lower compressive strength of the specimen, test machine generating mediate loads could satisfy 
this experimental requirement, and an universal SANS electronic testing machine was used in this study. One dimension strain compressive loading test was performed to study the behaviour of foamed concrete and a serial of load-displacement curves were obtained. It is worthy of note that this test method is only suitable for studying the mechanical behaviour of foamed concrete below the density of $1000 \mathrm{~kg} / \mathrm{m}^{3}$. Fig3 shows the photograph of the testing machine, and its maximum compressive loading value is $200 \mathrm{kN}$. The schematic of specimen installation is also shown in Fig3. The specimen is wrapped in steel sleeve with which confined condition is imposed on specimen. All specimens were loaded in one-dimension compression until complete densification of foamed concrete specimen arrived.

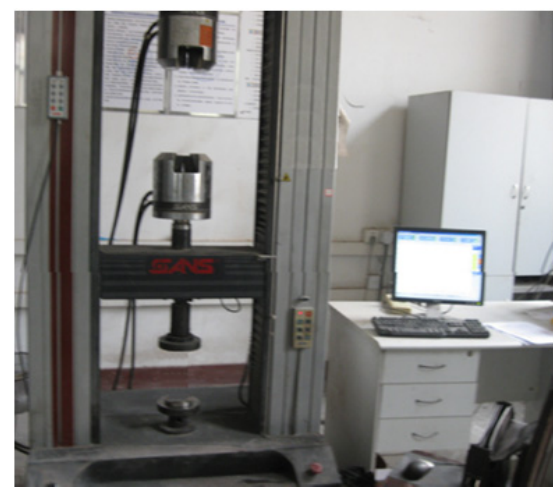

(a)

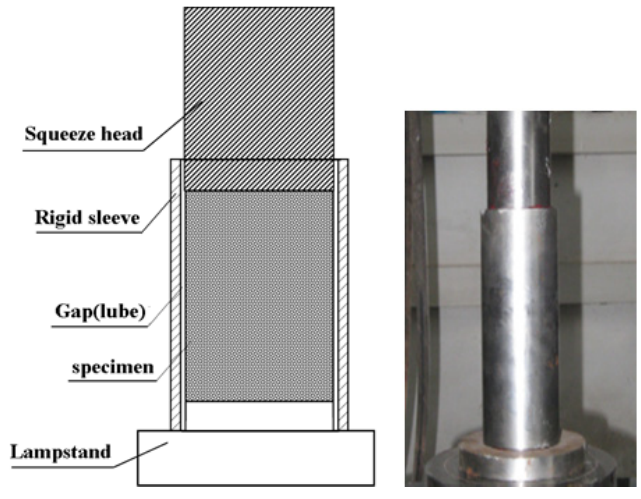

(b)

Figure 3. (a)Image of universal SANS electronic testing machine and (b)schematic of specimen installation

Displacement control of $1 \mathrm{~mm} / \mathrm{min}$ was employed in experiment, which lead to an effective strain rate of $1.6 \times 10^{-4} \mathrm{~s}^{-1}$. Complete compressive stress-strain curve of foamed concrete was calculated from load-displacement curve and shown in Fig4, which evidently indicated that the foamed concrete under one dimension strain loading condition experiences three regimes in its strain-stress curve, namely elastic regime, approximate plateau regime and densification regime, resembling other foam materials. Testing results also proves the experimental method used in our work is in line with expectation for overall understanding mechanical behaviour of foamed concrete.

\section{Testing Results}

Under one dimension strain compressive loading, stress - strain curves of tested foamed concrete with two densities are obtained and shown in Fig4. When stress exceeds yield limit of cell wall of foamed concrete the cell will be crushed and collapsed layer by layer, which leads to dramatic oscillation on stress-strain curve during testing. When all the layered-cells are crushed into lock the stress will arise sharply with increase of strain. The results also indicate that the strength and elastic modulus would decrease, whereas the strain(or compressibility) would increases with increase of porosity of foamed concrete.

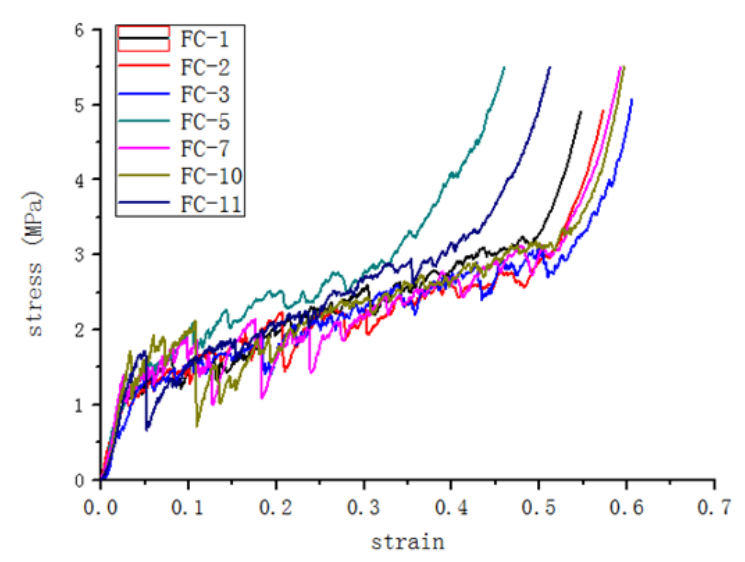

(a)

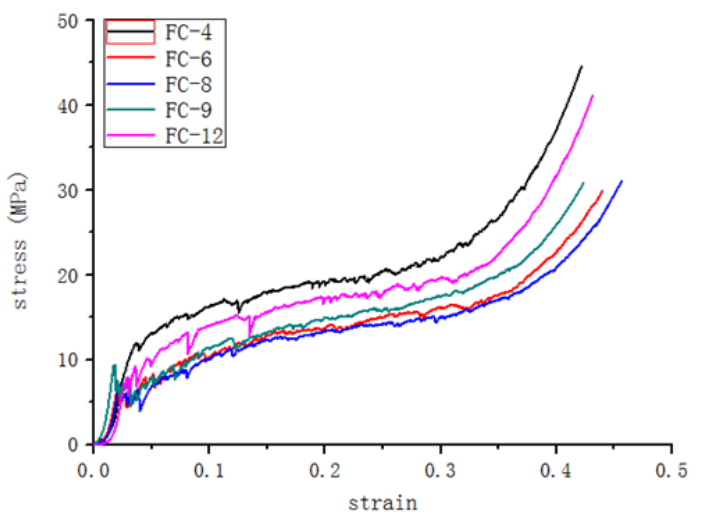

(b)

Figure 4. Stress - strain curve of foamed concrete with density of (a) of $400 \mathrm{~kg} / \mathrm{m}^{3}$ and (b) $800 \mathrm{~kg} / \mathrm{m}^{3}$ 
Experimental results imply that the deformation mechanism of foamed concrete under compression are completely different from that of foamed metal. Mechanism of behaviour of foamed concrete under one dimension strain loading compression can be observed from the remainder of the tested specimen after experiment, as shown in Fig5. Under external loads, one layer cellular cells of foamed concrete would experiences elastic deformation, brittle fracture, abrupt collapse and complete densification, and then this deformation and fracture mode would transmit into next layer up to all cell compaction. Just this deforming process in succession would lead to oscillation on stress-strain curve foamed concrete.

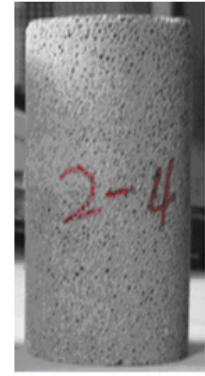

(a)

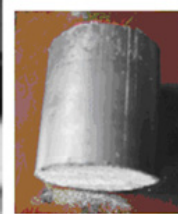

(b)

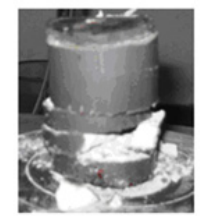

(c)

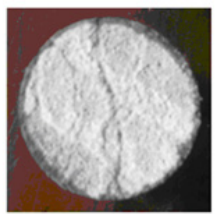

(d)

Figure 5. (a) Specimen before compression, (b)and(c)after compression, (d)cross-section of completely compacted foamed concrete

\section{Determination of Foamed Concrete's Elastic Modulus}

Elastic modulus of cellular materials is defined as the tangent slope of elastic regime of its stress-strain curve, and related to relative density of foamed concrete. The relationship between elastic modulus and relative density of cellular materials can be determined by(Gibson \& Ashby, 1997)

$$
\frac{E^{*}}{E_{s}}=C_{1} \phi^{2}\left(\frac{\rho^{*}}{\rho_{s}}\right)^{2}+C_{2}(1-\phi)\left(\frac{\rho^{*}}{\rho_{s}}\right)
$$

where $\boldsymbol{E}^{*}$ is the elastic modulus of cellular materials, $\boldsymbol{E}_{\boldsymbol{s}}$ is the elastic modulus of the matrix of cellular

materials, $\rho^{*}$ is the density of cellular materials, $\rho_{\boldsymbol{s}}$ is the density of the matrix, $\phi$ is the fraction of cell

edge and $(1-\phi)$ is that of cell wall. Formula (9) can be rewritten

$$
E^{*}=\frac{C_{1} E_{s} \phi^{2}}{\rho_{s}^{2}} \rho^{*^{2}}+\frac{C_{2} E_{s}(1-\phi)}{\rho_{s}} \rho^{*}=f\left(\rho^{*}\right)
$$

Formula(10) implies a clear functional relationship between elastic modulus and density of cellular materials.

Hence, for a given foamed concrete, namely $\boldsymbol{E}_{\boldsymbol{s}}, \boldsymbol{\phi}$ and $\boldsymbol{\rho}_{\boldsymbol{s}}$ are all constants, The relationship between elastic modulus and relative density of foamed concrete could be expressed as follows

$$
E^{*}(\rho)=\gamma+\beta \rho^{*}+\alpha \rho^{*^{2}}
$$

where $\gamma, \beta, \alpha$ are parameters determined by experiment. The elastic modulus of tested foamed concrete in this paper are plotted in Fig6. 


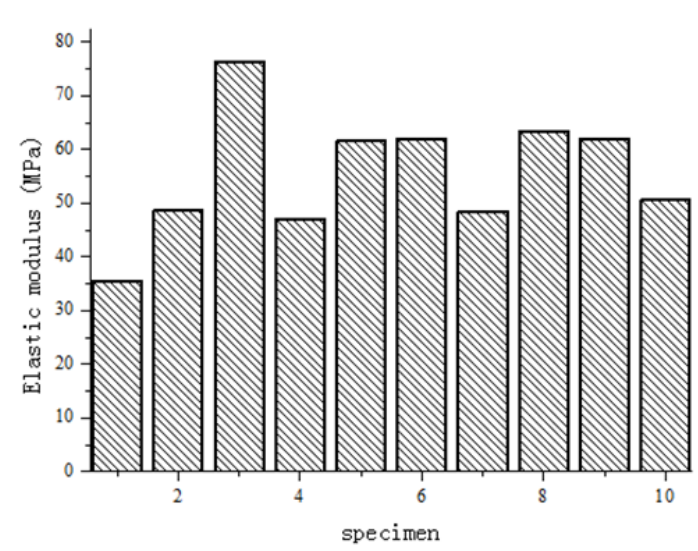

(a)

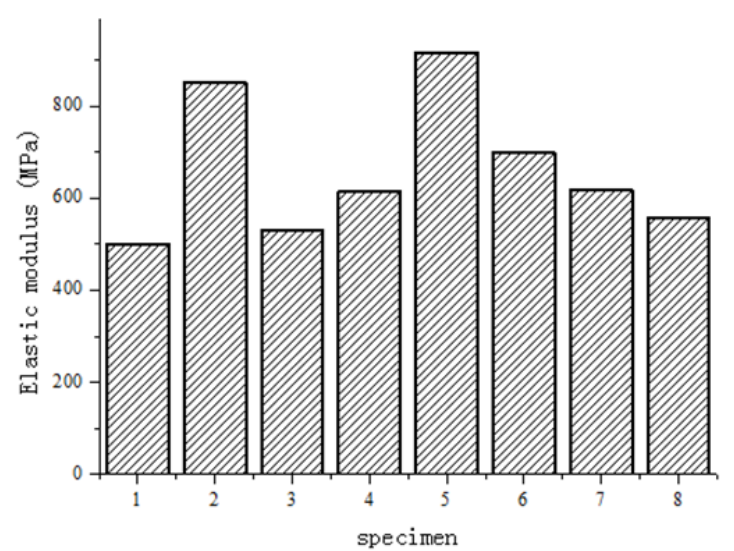

(b)

Figure 6. Elastic modulus of foamed concrete for density of (a) $400 \mathrm{~kg} / \mathrm{m}^{3}$ and $800 \mathrm{~kg} / \mathrm{m}^{3}$, respectively

From Fig6 elastic modulus of the tested foamed concrete would varies within a certain range and average values of elastic modulus are $55.56 \mathrm{MPa}$ and $651.6 \mathrm{MPa}$ for density of $400 \mathrm{~kg} / \mathrm{m}^{3}$ and $800 \mathrm{~kg} / \mathrm{m}^{3}$, respectively. Using formula (11) and testing results in Fig6, the relationship between elastic modulus and density of the tested foamed concrete is fitted by

$$
E^{*}(\rho)=-0.00201-0.53671 \rho^{*}+0.00169 \rho^{*^{2}}
$$

\section{Constitutive Equation and Yield Strength}

Constitutive equation is an important content in understanding mechanical properties of cellular materials and essential for the numerical computation. Compared with the stress-strain curve of foamed metal under compression, the plateau stress of foamed concrete oscillates dramatically instead of remains constant, and this characteristic was also observed in foamed ceramic's compressive test(Zhao, Luo \& Wang, 2012). This indicates different fracture mechanism of foamed concrete from that of foam metals, resulting from different meso-morphology and mechanical property of matrix of foam materials.

Study on constitutive relationship of some ductile foam materials such as foam aluminium and foam polymer have obtained more achievements(Lu, Huang \& Wang, 1997; Miltz \& Gruenbaum, 1998; Hu \& Liu, 1998; Lu \& Zhao, 1998; Wang, Yu, Wang \& Sun, 2004), however for brittle foam materials, e.g. foamed concrete and ceramic, have been in exploring stage because of the lack of feasible test standard. Only recently come important exploring research work had been done by researchers(Shang, Li, Chen \& Xiao, 2012; Xiong, 2008; Yan \& Yao, 2007).

There are two main type of constitutive equations for foam materials, namely empirical one and semiempirical one, such as the constitutive equation proposed by Bigg(Bigg, 1981), and it is based on Vogit body. Another is of low density foam plastic proposed by Shuttleworthr et al(Shuttleworth, Shestopal \& Goss, 1985). During studying constitutive relationship of foam materials under compression loading, the compressive stress can be expressed by two parts: one is elastic modulus indicating resistant property against compressive deformation, and another is the shape function relating to strain used to describe deformation characteristic of foam materials during compression. Among them, typical constitutive model of foam material proposed by Rusch is expressed as follows(Rusch, 1970)

$$
\sigma=E^{*}(\rho) g(\varepsilon)
$$

where $g(\varepsilon)$ is a nonlinear shape function. There're several shape functions that could be used to describe the deformation properties of foam materials under compression, e.g. Boltzman function, Lorentzian function and series of powers(Miltz, Ramon \& Mizrahi, 1989). The former two functions could exactly reveal the deforming characteristic of foam materials before strain lock. Here the five-order power function is used to describe the full 
deformation process and be generally written by

$$
g(\varepsilon)=a_{0}+a_{1} \varepsilon+a_{2} \varepsilon^{2}+a_{3} \varepsilon^{3}+a_{4} \varepsilon^{4}+a_{5} \varepsilon^{5}
$$

where $a_{0}, a_{1}, a_{2}, a_{3}, a_{4}, a_{5}$ are constants determined by experiment. So using formula (14) and (13), constitutive equation of foam materials under compression can be rewritten

$$
\sigma=E^{*}(\rho)\left(a_{0}+a_{1} \varepsilon+a_{2} \varepsilon^{2}+a_{3} \varepsilon^{3}+a_{4} \varepsilon^{4}+a_{5} \varepsilon^{5}\right)
$$

Considering when $\boldsymbol{\varepsilon}=0$, stress $\boldsymbol{\sigma}=0$, leading to $\boldsymbol{a}_{0}=0$. Substituting formula (12) into (15), the constitutive equation of foamed concrete is written as follows

$$
\sigma=\left(-0.00201-0.53671 \rho^{*}+0.00169 \rho^{* 2}\right)\left(a_{1} \varepsilon+a_{2} \varepsilon^{2}+a_{3} \varepsilon^{3}+a_{4} \varepsilon^{4}+a_{5} \varepsilon^{5}\right)
$$

Therefore, determination of shape function is the key step to determine constitutive equation of foamed concrete, and these constants are determined by fitting from experimental data. In this work, two typical shape functions for two densities of foamed concrete are given

$$
\begin{array}{r}
g(\varepsilon)=0.759776135 \varepsilon-6.443092659 \varepsilon^{2}+28.55727745 \varepsilon^{3}-61.09185054 \varepsilon^{4}+52.0056677 \varepsilon^{5} \\
\left(\text { for } 400 \mathrm{~kg} / \mathrm{m}^{3}\right)
\end{array}
$$

Leading to corresponding constitutive equations

$$
\begin{array}{rr}
\sigma=42.33016 \varepsilon-358.8704 \varepsilon^{2}+1591.03987 \varepsilon^{3}-3403.67075 \varepsilon^{4}+2897.44325 \varepsilon^{5} & \left(\text { for } 400 \mathrm{~kg} / \mathrm{m}^{3}\right) \\
\sigma=377.08657 \boldsymbol{\varepsilon}-3315.33815 \varepsilon^{2}+15041.54604 \varepsilon^{3}-34055.07603 \varepsilon^{4}+31828.97978 \varepsilon^{5} \\
(19) \\
\left(\text { for } 800 \mathrm{~kg} / \mathrm{m}^{3}\right) \quad(20)
\end{array}
$$

Fig6 illustrates the comparison between experimental stress-strain curves and constitutive equation of two densities of foamed concrete. The constitutive equations agree well with the experimental results.

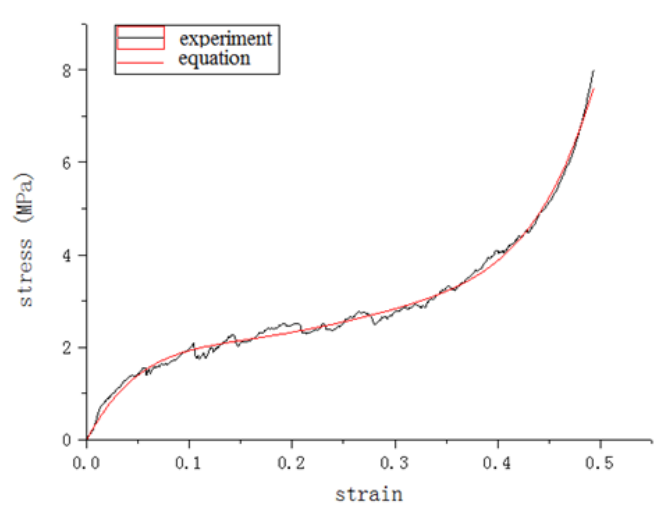

(a)

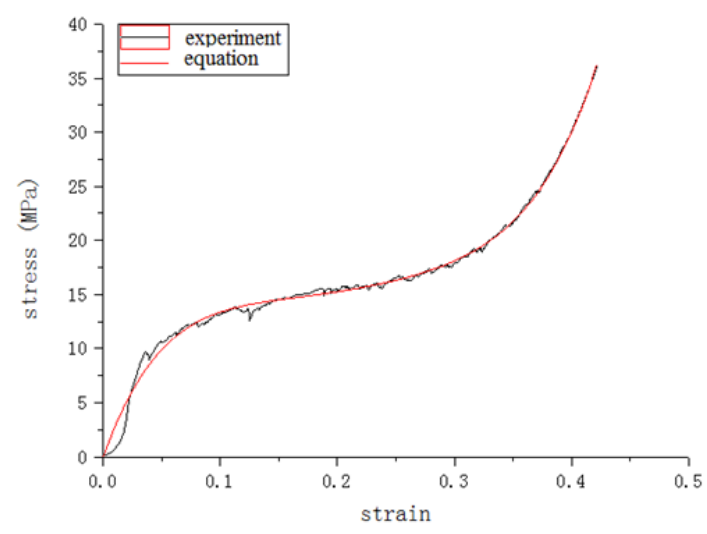

(b)

Figure 6. Stress-strain curves from experiment and constitutive equation model for density of (a) $400 \mathrm{~kg} / \mathrm{m}^{3}$ (test FC-5) and (b) $800 \mathrm{~kg} / \mathrm{m}^{3}$ (test FC-4)

The constitutive equation (19) and(20) can be used not only in the numerical simulation but also in the yield stress calculation. Fig7 gives experimental yield strain and stress of tested foamed concrete. 


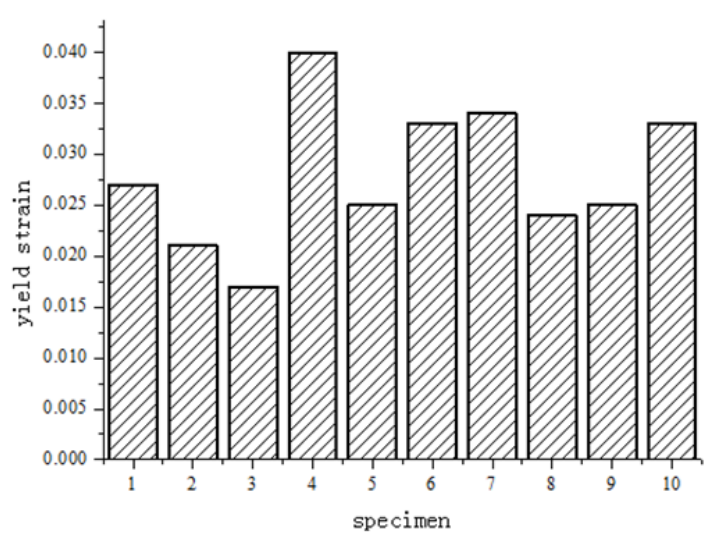

(a)

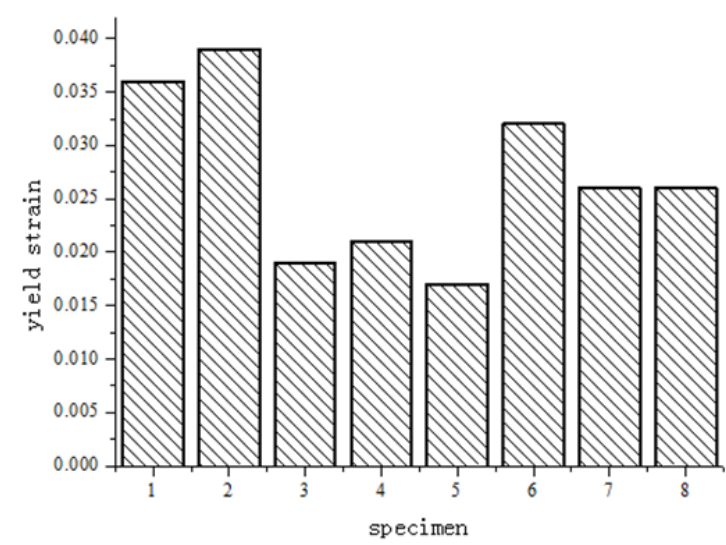

(c)

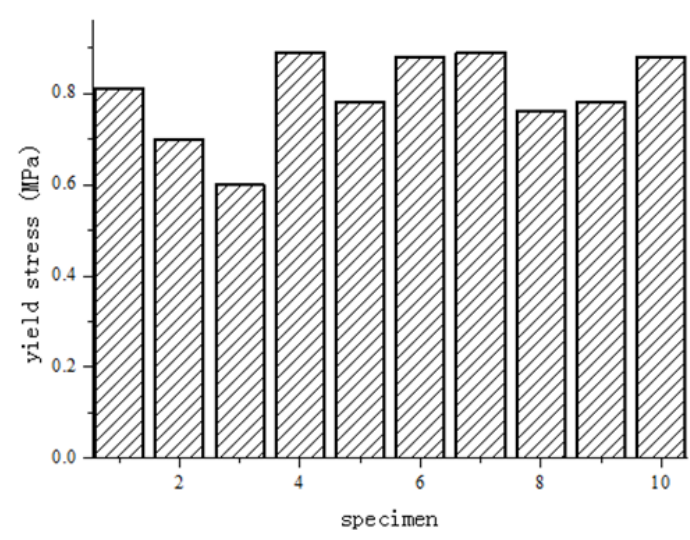

(b)

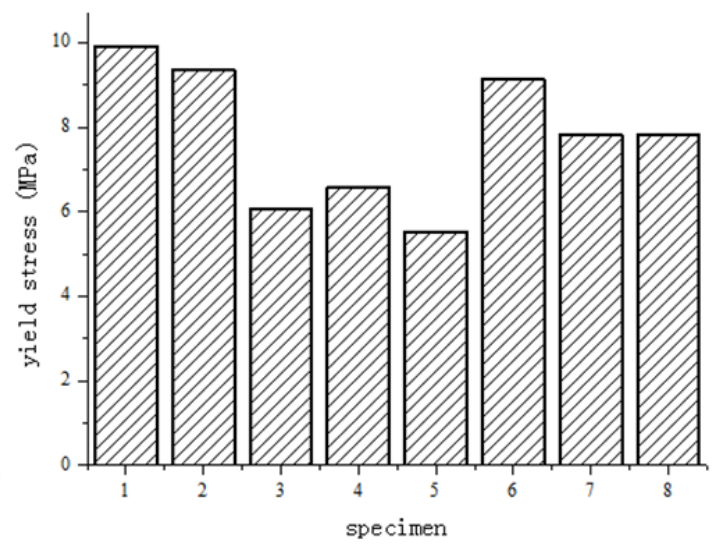

(d)

Figure 7. (a)(c)Yield strain and (b)(d)yield stress of foamed concrete for density of (a) $400 \mathrm{~kg} / \mathrm{m}^{3}$ and $800 \mathrm{~kg} / \mathrm{m}^{3}$, respectively

From Fig7 the values of yield strain and yield stress vary randomly within a certain range, especially for foamed concrete with higher density.

\section{Energy Absorption of Foamed Concrete}

Foamed concrete is usually used as filling materials in protective structures, and during defense of blast and impact foamed concrete plays the role in attenuating or absorbing blast and impact energy. Energy absorbing property of foamed concrete mainly comes from its long "plateau regime" of the three-regime stress-strain curve $^{[1]}$ as shown in Fig4. Therefore, foamed concrete has a strong blast mitigation and energy absorption property when subjecting to external force, which makes foamed concrete an excellent and low cost blast resistant material. The absorbing energy of foamed concrete under one dimension strain loading condition equals to the area beneath stress-strain curve, which can be computed by(Li, Magkiriadis \& Harrigen, 2006)

$$
\boldsymbol{E}=\int_{0}^{\varepsilon} \sigma \mathrm{d} \boldsymbol{\varepsilon}
$$

where $\boldsymbol{\varepsilon}$ is arbitrary strain on stress-strain curve. Fig8 shows the energy absorption efficiency curves versus the stress-strain curve of two density of foamed concrete, as well as the stress-strain curve. 


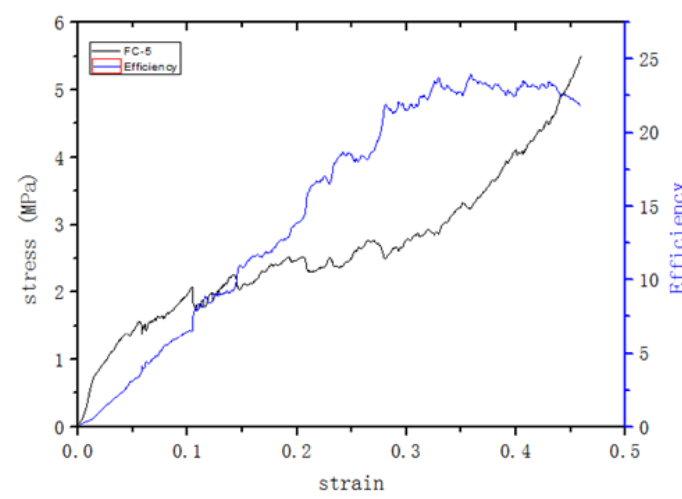

(a)

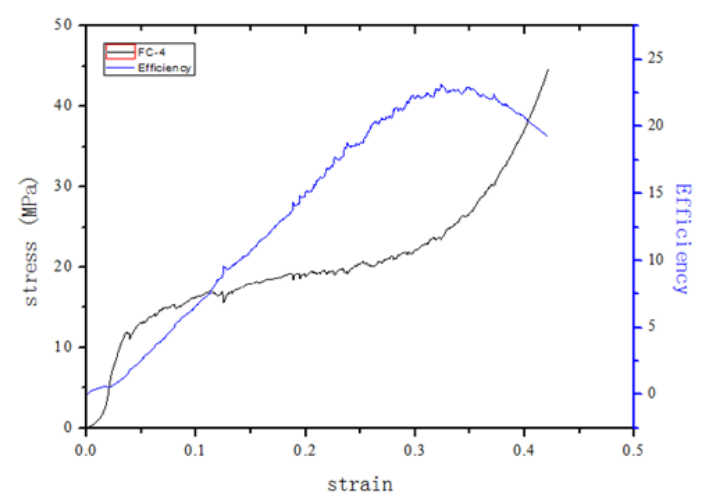

(b)

Figure 8. Stress-strain curve and corresponding energy absorption efficiency of foamed concrete at density of (a) $400 \mathrm{~kg} / \mathrm{m}^{3}$ and (b) $800 \mathrm{~kg} / \mathrm{m}^{3}$, respectively

Densification strain and plateau stress are two characteristic parameters describing the mechanical behaviour of cellular materials, and it can be accurately determined from the compressive stress-strain curve. Several methods can be used to determine densification strain, but there exist great uncertainties in data via these methods(Li, Magkiriadis \& Harrigen, 2006). Therefore, Li et al proposed an energy absorption efficiency method (Li, Magkiriadis \& Harrigen, 2006) to uniquely determine densification strain, and the energy absorption efficiency can be calculated by the following equation

$$
\eta(\varepsilon)=\frac{1}{\sigma(\varepsilon)} \int_{\varepsilon_{y}}^{\varepsilon} \sigma(\varepsilon) \mathrm{d} \varepsilon
$$

where $\varepsilon_{y}$ is yield strain corresponding to the start of plateau regime. When set $\mathrm{d} \eta(\varepsilon) /\left.\mathrm{d} \varepsilon\right|_{\mathcal{E}=\varepsilon_{d}}=0$, the energy absorption efficiency will reaches its maximum at which foamed concrete is completely compacted. Hence the plateau stress can be determined by(Xiong, 2008)

$$
\sigma_{\mathrm{pl}}=\frac{\int_{\varepsilon_{y}}^{\varepsilon_{\mathrm{d}}} \sigma(\varepsilon) \mathrm{d} \varepsilon}{\varepsilon_{\mathrm{d}}-\varepsilon_{y}}
$$

where $\varepsilon_{d}$ is the densification strain. Using formula (23), unit volume absorbing energy from the yield point up to the densification, densification strain and plateau stress of tested foamed concrete are calculated and plotted in Fig9.

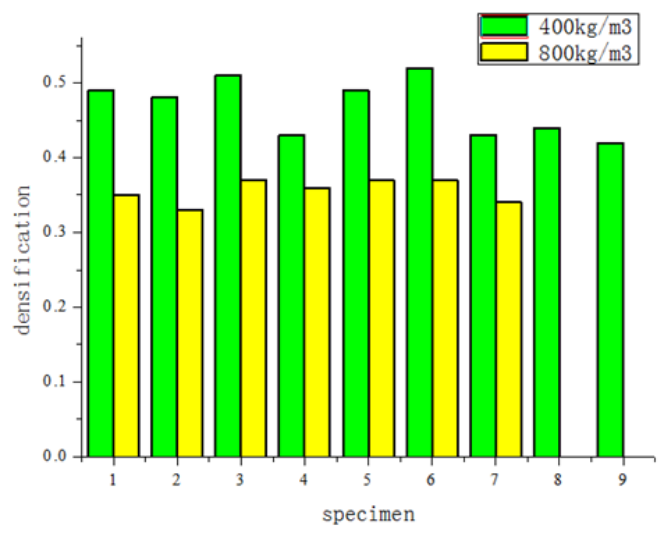

(a)

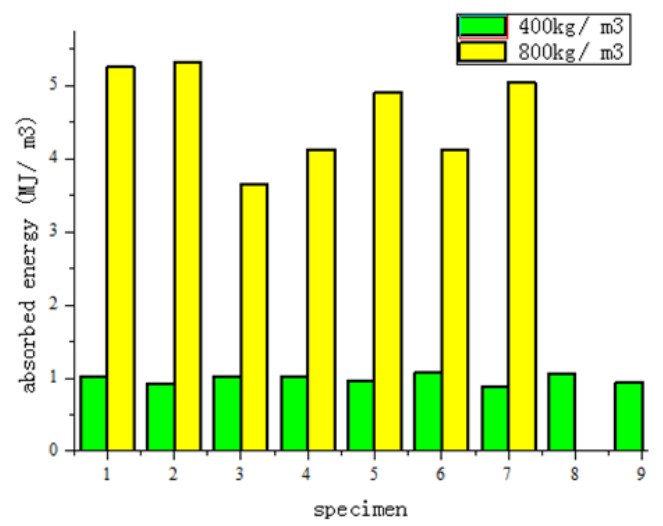

(b) 


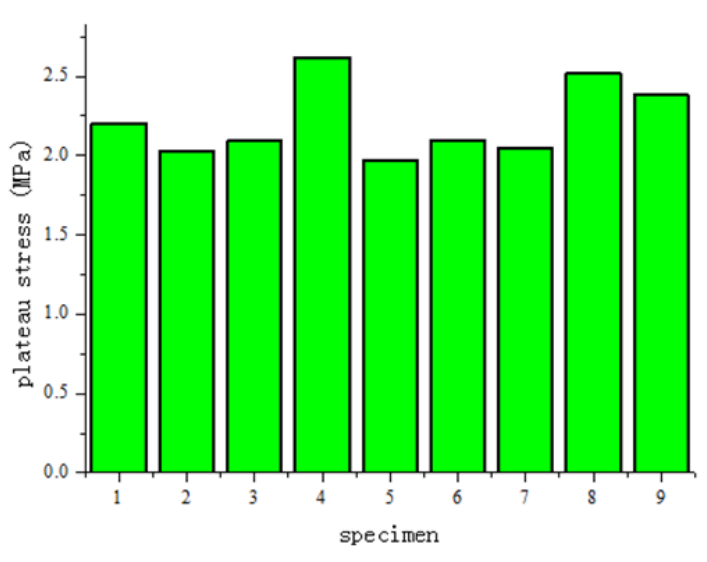

(c)

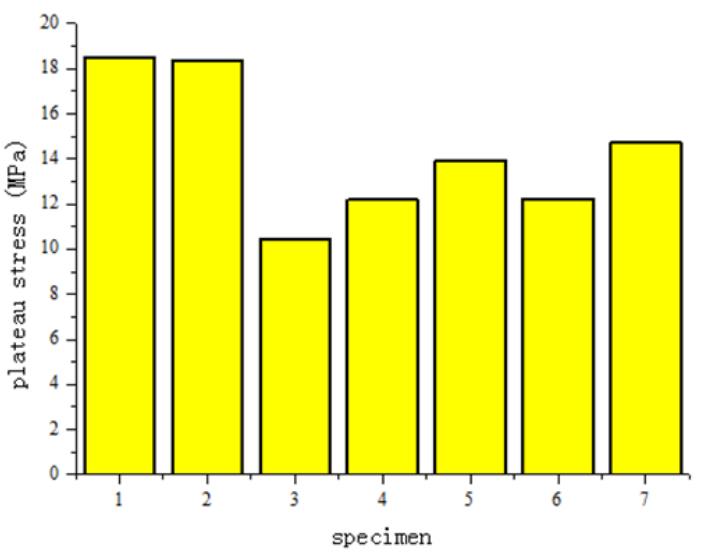

(d)

Figure 9. (a)Densification, (b)unit volume absorbed energy and plateau stress for density of (c) $400 \mathrm{~kg} / \mathrm{m}^{3}$ and (d) $800 \mathrm{~kg} / \mathrm{m}^{3}$ of foamed concrete, respectively

Fig9 demonstrates that densification strain of foamed concrete would decrease while the absorbed energy increase with increment of density. Considering energy absorption of common concrete up to full damage far less than that foamed concrete, it can be imagined there exists limit density within which foamed concrete has optimal energy absorbing effects.

\section{Conclusion}

Mechanical behaviour and properties of foamed concrete are important issues for correct understanding its characteristic of mitigating blast loads in defense engineering. In this study, full stress-strain relationship of foamed concrete was exploited using one dimension strain compressive loading methods, and the constitutive equations for two densities of foamed concrete are proposed. The entire three regimes of stress-strain behavior of foamed concrete have been observed, which can better contribute to collapse layer by layer and mechanism of energy absorption during compression. The elastic modulus, compressive strength, densification strain and absorbing energy were also analyzed in this study. In addition, the new testing method used in this study can be effective to construct the standard of foamed concrete's compressive experiment, for common test method used in usual concrete compression was no longer available for studying behaviour of foamed concrete. The constitutive relationship obtained in this research also demonstrates the potential properties of attenuation and resistance against external dynamic impact for foamed concrete, which indicates that the foamed concrete should be an excellent, cheaper and broad great promise in applications as a core material in defense engineering.

\section{Acknowledgement}

The author would like to acknowledge the material support of Professor Lu Zhongyuan and Niu Yunhui in undertaking this research work and the following organization: National Key Laboratory of Non-metal Compound and Functional material of Sichuan Province, Southweat University of Science and Technology and State Key Laboratory of Explosion Science and Technology (Beijing Institute of Technology).

\section{References}

Weigler, H., \& Karl, S. (1980). Structural lightweight aggregate concrete with reduced density-lightweight aggregate foamed concrete. International Journal of Lightweight Concrete, 2(2), 101-104.

Jones, M. R., \& Mccarthy, A. (2005). Preliminary views on potential of foamed concrete as a structural material. Magazine of Concrete Research, 57(1), 21-31.

Tikalsky, P. J., Pospisil, J., \& Macdonald, W. A. (2004). A method for assessment of the freeze-thaw resistance of preformed foam cellular concrete. Cement and Concrete Research, 34(5), 889-893.

Zollo, R. F., \& Hays, C. D. (1998). Engineering material properties of a fiber reinforced cellular concrete. $A C I$ Materials Journal, 95(5), 631-635.

Hoff, G. C.(1972). Porosity-strength considerations for cellular concrete. Cement and Concrete Research, 2(1), 91-100. 
Pan, Z. H., Fujiwara, H., \& Wee, T. H. (2007). Preparation of high performance foamed concrete from cement, sand and mineral admixtures. Journal of Wuhan University of Technology(Material Science Edition), 22(2), 295-298.

Ahmad, Z. A. M., \& Li, Q. M. (2009). Investigation on penetration resistance of foamed concrete. Structures and Buildings, 162, 77-85.

Shang, S. Q., Li, D., Chen, X. M. \& Xiao, Z. X.(2012). Studied on Uniaxial Compressive Mechanical Properties About Foamed Concrete. Journal of Wuhan University of Technology, 34(12), 24-29.

Zhou, S. E., Lu, Z. Y., Jiao, L., \& Li, S. X. (2010). Compression property and compression strength model of foamed concrete[J]. Journal of Wuhan University of Technology, 32(11), 9-13.

Xiong, Y. Q., \& Yao, Q. F.(2010). Experimental study on the stress-strain curve of porous lightweight concrete[J]. Sichuan Building Science, 36(2), 228-232.

Li, G., L., Guo, W. G., Zhao, R., \& Shi, Y. J. (2012). Mechanical properties and phenomenological constitutive model of lightweight foamed concrete. Journal of materials Science \& Engineering, 30(3), 428-431.

Mohd, Z. A., Mujahid, A., Zaidi, A., \& Ismail, A. R. (2010). Physical behaviour of foamed concrete under uniaxial compressive load: Confined compressive test. Modern Applied Science, 4(2), 126-132.

Xiong, Y. Q. (2008). Study on Damage Evolution Rule and Damage Model of Multi-ribbed Composite Wall, Beijing Jiaotong University.

Abdul, R. I. (2008). Morphology and physical behaviour of foamed concrete under uniaxial compressive load: standard unconfined compressive test. UTHM Research Technical Report, pp1-10.

Zaudi, A. M., Rahman, A. L., \& Zaidi, A. (2008). Behaviour of fiber reinforced foamed concrete: indentation test analysis. Proceeding of the seminar on geotechnical engineering UTHM, pp 92-101.

Luo, W. C. (2011). Study on mechanical properties of ceramic foams and application in defence works. University of Science and Technology of China.

Liu, F., Zhao, K., Wang, X. J., \& Ren, H. Q. (2007). A study on SHPB method of soft and porous materials. Journal of Experimental Mechanics, 22(1), 20-26.

Zhao, K., Luo, W. C., \& Wang, X. J. (2012). Test for mechanical behaviour of clay ceramic foam. Journal of Vibration and Shock, 31(21), 50-57.

Gibson, L. G., \& Ashby, M. F. (1997). Cellular solids: structure and properties, 2nd edit. Cambridge University Press.

Lu, Z. X., Huang, Z. P., \& Wang, R. (1997). The strain-rate dependent constitutive relation and mechanical properties of open-cell foam plastics in tension. Acta Polymerica Sinica, 4, 387-392.

Miltz, J., \& Gruenbaum, G. (1998). Evaluation of cushion properties of plastic foams compressive measurements. Polymer Engineering and Science, 1010-1014.

Hu, S. S., \& Liu, J. F. (1998). Study of the constitutive relationship of rigid polyurethane foam. Acta Mechanical Sinica, 30(2), 151-156.

Lu, Z. X., \& Zhao, M. J. (1998). Research progress in mechanical property of foam plastic. Mechanics in Engineering, 20(2), 1-9.

Wang, R. H., Yu, J. L., Wang, F., \& Sun, L. (2004). A theoretical and experimental study on the quasi-static constitutive model of aluminum foams. Acta Mechanical Sinica, 36(6), 673-679.

Yan, X. Z., \& Yao, Q. F. (2007). Experimental study on the mechanical property of foamed concrete. Industrial Construction, 37, 962-964.

Bigg, D. M. (1981). Predicting the shock mitigating properties of thermoplastic foams. Polymer Engineering and Science, 21(9), 548-556.

Shuttleworth, R. W., Shestopal, V. O., \& Goss, P. C. (1985). Open-cell flexible polyurethane foams: Comparison of static and dynamic compression properties. Journal of Application of Polymer Science, 30, 333-343.

Rusch, K. C. (1970). Load-compression behaviour of flexible foams. Journal of Application of Polymer Science, 13, 2297-2311.

Miltz, J., Ramon, O., \& Mizrahi, S. (1989). Mechanical behaviour of closed cell plastic foams used as cushing materials. Journal of Application of Polymer Science, 38, 281-290. 
Li, Q. M., Magkiriadis, I., \& Harrigen, J. J. (2006). Compressive strain at the onset of desification of cellular solids. Journal of Cellular Plastics, 42(5), 371-392.

\section{Copyrights}

Copyright for this article is retained by the author(s), with first publication rights granted to the journal.

This is an open-access article distributed under the terms and conditions of the Creative Commons Attribution license (http://creativecommons.org/licenses/by/3.0/). 